\title{
A humanização e a formação médica na perspectiva dos estudantes de Medicina da UFRN - Natal - RN - Brasil
}

\author{
Humanization of undergraduate medical \\ education from the perspective of medical \\ students at the Federal University in Rio Grande \\ do Norte, Brazil
}

\author{
Antonia Núbia de Oliveira Alves ${ }^{\mathrm{I}}$ \\ Simone da Nóbrega Tomaz Moreira ${ }^{\mathrm{I}}$ \\ George Dantas de Azevedo ${ }^{\mathrm{I}}$ \\ Vera Maria da Rocha ${ }^{\mathrm{I}}$ \\ Maria José Vilar ${ }^{\mathrm{I}}$
}

PALAVRAS-CHAVE

- Estudantes de medicina

- Educação médica

- Humanização

- Pesquisa qualitativa
Recebido em: 09/06/2008 Reencaminhado em: 30/03/2009 Aprovado em:14/04/2009

\begin{abstract}
RES U M O
Este estudo, por meio de uma abordagem qualitativa, busca compreender a percepção dos estudantes de Medicina da Universidade Federal do Rio Grande do Norte (UFRN) acerca da humanização no contexto da formação médica. Foi utilizada a técnica de grupo focal, envolvendo uma equipe multidisciplinar com profissionais das áreas de antropologia, psicologia e medicina, que estudou dois grupos de nove estudantes do último ano do curso. Os dados foram analisados pela técnica de análise de conteúdo temática categorial, da qual emergiram três categorias: relação estudante-paciente, ensino-aprendizagem e relação estudante-professor. A primeira categoria permite identificar que a experiência do contato do estudante com o paciente é essencial à construção de uma identidade profissional humanizada. Em relação à segunda categoria, percebe-se que professores sem capacitação nas práticas pedagógicas, inerentes à profissão de professor, e a dicotomia teoria-prática dificultam a formação autônoma do conhecimento e uma visão integral do indivíduo. Da terceira categoria emergiram duas subcategorias antagônicas (professor-modelo e relações assimétricas), que refletem a importância da postura ético-humanista do professor em detrimento de uma atitude autoritária para a construção da identidade profissional do estudante. Esses dados apontam aspectos da formação médica que podem respaldar uma discussão acerca da humanização no contexto das novas diretrizes curriculares.
\end{abstract}

\section{A B S T R A C T}

This study used a qualitative approach to understand the perspective of medical students at the Federal University in Rio Grande do Norte, Brazil, concerning humanization in the context of medical training. A focus group technique was used, involving a multidisciplinary team from anthropology, psychology, and medicine that studied two groups of nine students each from the last year of medical school. Data were submitted to categorical thematic content analysis, revealing three categories: the student-patient, teaching-learning, and student-professor relationships. The first category showed that the student's experience of contact with patients is essential for constructing a humanized professional identity. In the second category, professors with no training in inherent pedagogical practices, plus the dichotomy between theory and practice, hinder the autonomous formation of knowledge and a comprehensive view of the individual. Two opposing sub-categories emerged from the third category (model professor and asymmetric relations) that reflect the importance of the professor's ethical-humanist stance rather than an authoritarian attitude in the construction of the student's professional identity. These data highlight aspects of medical training that can substantiate a discussion of humanization in the context of the new curricular guidelines. 


\section{INTRODUÇÃO}

O grande avanço tecnológico ocorrido na área da saúde no decorrer do século 20 provocou uma transformação no perfil de atuação do médico, que foi se tornando, cada vez mais, um especialista, um profundo conhecedor de exames complexos e especializados, capaz de emitir diagnósticos precisos e de propor tratamentos eficazes. Nesse processo, a relação médico-paciente ficou prejudicada, pois houve uma supervalorização da doença e de seus sintomas em detrimento da singularidade do paciente ${ }^{1}$.

Para acompanhar todo esse desenvolvimento da medicina, a formação médica, até então sustentada pelo modelo biomédico, tornou-se cada vez mais especializada e fragmentada, com ênfase no conhecimento técnico, não sendo capaz de preparar o médico para assistir o paciente em seus aspectos psicológicos e sociais ${ }^{2}$.

Traverso-Yépez e Morais ${ }^{3}$ (p. 80) concordam e acrescentam que a formação médica deve incluir o papel da experiência profissional e das práticas cotidianas, ampliando, assim, a relação entre médico-paciente e deixando claro que não existe um que não sabe, mas dois que sabem coisas distintas. Decorre daí a necessidade de superar essa visão antropocêntrica e individualista do modelo biomédico, acreditando que o agir do profissional de saúde deveria ser baseado mais na escuta e no diálogo do que na imposição de "receitas".

Diante desse cenário, o modelo biopsicossocial surge a partir da necessidade de buscar uma visão holística do homem, em que os aspectos psicológicos e sociais são intrinsecamente vinculados aos aspectos biológicos, de forma a ampliar a capacidade de autonomia do paciente ${ }^{4}$ (p. 208). Cada vez mais, percebe-se a necessidade de formar médicos reflexivos, éticos, conscientes e sensíveis à pessoa humana e ao seu contexto social.

No campo das políticas públicas direcionadas à saúde da população e à educação dos profissionais de saúde, tem havido vários avanços, destacando-se a formulação das diretrizes curriculares dos cursos de graduação da área da saúde, que, de forma uníssona, enfatizam um lugar de destaque para os aspectos ético-humanísticos na formação desses profissionais. No contexto da geração de conhecimento relacionado a esse tema, tem se dado maior enfoque à produção de substrato teórico para orientar as mudanças curriculares e a relatos de experiências individuais sobre a percepção do corpo docente acerca da humanização na formação dos novos médicos. Em virtude disso, este trabalho busca compreender a percepção dos estudantes de Medicina da UFRN acerca da humanização no contexto da formação médica, a fim de obter subsídios para respaldar uma discussão sobre aspectos referentes a essa questão.

\section{PERCURSO METODOLÓGICO}

Foi realizado um estudo fundamentado na abordagem qualitativa, que permite compreender os significados atribuídos aos fenômenos ${ }^{5}$. O estudo obteve aprovação do Comitê de Ética em Pesquisa da UFRN (protocolo no 68/05), e, após a concordância com os propósitos da pesquisa, todos os estudantes assinaram o Termo de Consentimento Livre e Esclarecido.

A técnica utilizada para obtenção dos dados da pesquisa foi a de grupo focal ${ }^{5,6}$. Os estudantes foram selecionados no Complexo Hospitalar e de Saúde da UFRN de novembro de 2006 a fevereiro de 2007. Foram realizados dois grupos focais, com duração média de 90 minutos, compostos de nove estudantes do último ano do curso de Medicina pertencentes ao currículo anterior à implantação do novo projeto pedagógico. O primeiro grupo foi composto por cinco mulheres e quatro homens, e o segundo, por três mulheres e seis homens. A amostragem foi intencional ${ }^{6}$, buscando-se abranger o problema em suas múltiplas dimensões, seguindo critérios que levaram em conta a disponibilidade e o interesse pela temática abordada. O fechamento amostral foi determinado pela técnica de saturação, quando se tornaram evidentes as repetições e redundâncias de informações ${ }^{7}$ (p. 681). As falas dos participantes foram gravadas, transcritas e relidas, produzindo um texto de quinze páginas, em espaço simples, tendo sido garantidos o sigilo e o anonimato dos participantes.

A discussão do grupo foi conduzida pelo moderador e um secretário, sendo guiada, mas não limitada, pela seguinte questão norteadora: Como é percebida a humanização no processo da sua formação médica? Desse modo, foi iniciado o debate, acolhendo e valorizando os sentimentos, as experiências e as angústias vividas pelos estudantes durante a sua formação acadêmica. O moderador foi responsável pela condução do grupo, tendo a função de solicitar esclarecimentos, aprofundar pontos específicos, estimular a participação homogênea do grupo e proceder à finalização da discussão com os participantes.

O secretário fazia as anotações de expressões, gestos, falas sussurradas e discordâncias não faladas no diário de campo ${ }^{5}$.

A análise dos dados foi realizada por meio da técnica de análise de conteúdo temática categorial, fundamentada em Minayo ${ }^{5}$ e Bardin ${ }^{8}$. Neste sentido, o processo analítico compreendeu as seguintes fases: leitura flutuante, constituição do corpus e formulação de hipóteses e objetivos.

A leitura flutuante consistiu no contato exaustivo com o material transcrito. Foi feita uma leitura minuciosa das falas transcritas para compreender os significados, as argumentações e as justificativas que conciliaram as práticas discursivas. 
Na constituição do corpus, ocorreu a organização do material, de forma que respondesse às normas de validade, tais como: exaustividade (contemplar todos os aspectos levantados na discussão); representatividade (conter a representação do universo pretendido); homogeneidade (obedecer a critérios precisos de escolha em termos de tema, técnicas e interlocutores); e pertinência (estar adequado aos objetivos do trabalho) ${ }^{9}$ (p. 39).

A formulação de hipóteses e objetivos consistiu na seleção das unidades de análise mediante o processo de categorização $a$ posteriori ou empírica, por meio da qual emergiram categorias que foram descritas e discutidas a partir do referencial teórico existente.

\section{RESULTADOS E DISCUSSÃO}

A partir do processo de categorização, emergiram três categorias, sete subcategorias e 152 unidades de análise, conforme mostra a Tabela 1.

Tabela 1

Categorias e subcategorias obtidas a partir da percepção dos estudantes sobre a humanização na formação médica

\begin{tabular}{l|l|c}
\hline \multicolumn{1}{c|}{ Categoria } & \multicolumn{1}{|c}{ Subcategoria } & Unidade de análise (n) \\
\hline 1. Relação estudante-paciente & 1.1 Visão integral (holística) do ser humano & 22 \\
2. Ensino-aprendizagem & 2.1 Didática & 18 \\
& 2.2 Dicotomia teoria e prática & 22 \\
& 2.3 Contato com a comunidade & 11 \\
& 2.4 Integralidade & 15 \\
3. Relação & 3.1 Professor modelo & 25 \\
estudante-professor & 3.2 Relações assimétricas & 39 \\
\hline
\end{tabular}

Como reflexo de múltiplos fatores - entre eles a incorporação crescente de tecnologias às práticas de saúde e a fragmentação do conhecimento médico -, o ensino da medicina, ao longo das últimas décadas, foi desenvolvido preferencialmente em cenários hospitalares, pautado no conhecimento técnico e especializado, centrado na figura do professor, em detrimento da atenção básica em saúde e dos aspectos humanísticos relacionados à profissão.

Neste estudo, que analisa a percepção dos estudantes sobre os aspectos relacionados à humanização durante a formação médica, evidencia-se que, na relação estudante-paciente, várias situações são vivenciadas e frequentemente impressas na formação, ou seja, na construção da identidade profissional do futuro médico ${ }^{10,11,12}$. Isto pode ser evidenciado a partir da análise das seguintes falas: Ver o sofrimento das pessoas, nas mais diferentes formas, nas suas mais amplas possibilidades, como físicas, financeiras, sociais, psicológicas... é assim que a gente tem um vislumbre do que é o ser humano na sua complexidade.
No entanto, a despeito da sensibilidade demonstrada, não sobra espaço durante a formação para que o estudante divida ou expresse suas emoções. Muitas vezes, ele tem que escondê-las, por receio de ser "acusado" de ser muito frágil, sensível, "mole" e, portanto, "não servir para ser médico"13 (p.155); 14,15 (p. 715): Eu me choquei muito quando vi uma criancinha deitada no banco, com a mãe chorando e dizendo: "não tem jeito, não tem jeito!!!" Íamos para a sala de aula e parei, um colega disse: "vamos, deixe de sentimentalismo e seja forte".

Na maioria dos cursos de Medicina, os estudantes são treinados em operar equipamentos e fazer leituras de variáveis biológicas, sem espaço para desenvolver habilidades e competências que os capacitem a reconhecer o ser humano como unidade biopsicossocial e espiritual, inserido num contexto epidemiológico e sociocultural.

As falas seguintes demonstram a necessidade que os estudantes têm de uma relação mais próxima e mais humanizada com o paciente ${ }^{16,17,18}$ : 
O contato com o paciente é essencial pra nossa formação, por mim seria antes, pois teríamos mais tempo para aprender a lidar com o sofrimento, com os sentimentos. Isso possibilitaria identificar as reais causas da doença, já que nosso ensino é voltado para a doença e não para a saúde.

[...] em relação à humanização [...] há consciência realmente de que o médico que se forma hoje não tem nenhuma formação humanizada e isso se reflete na imaturidade do médico que se forma.

Esse contexto de deterioração dos conteúdos humanísticos no processo ensino-aprendizagem diz respeito ao perfil do corpo docente, que, historicamente, na maioria das escolas médicas, é constituído por médicos especialistas, com formação direcionada à prática clínica e pouco capacitado para as práticas pedagógicas, inerentes à profissão de professor ${ }^{19}$ (p. 111). O processo de ensinar define-se pela obtenção da aprendizagem do estudante e não pela intenção (ou objetivo) do professor ou por uma descrição do que ele faz em sala de aula. A relação entre o que o professor faz e a efetiva aprendizagem do estudante é o que, mais apropriadamente, pode ser chamado de ensinar ${ }^{20}$.

No estudo, observa-se o reflexo desse fato na percepção, pelos estudantes, do contexto da humanização nas questões relacionadas à didática dos professores, conforme se observa nas falas a seguir:

[...] muitas vezes, os professores só se preocupam em dar a sua aula, ou seja, passar pelo conteúdo sem se preocupar se aprendemos alguma coisa ou não.

Eu noto que mesmo na nossa área (Medicina), muitos deles (professores) são competentes como profissionais, mas não têm nenhuma capacidade de ensinar... ensinar significa ter técnica, saber como abordar um assunto para uma pessoa que não sabe.

Na visão dos estudantes, outro aspecto relacionado ao processo ensino-aprendizagem é a dicotomia existente entre a teoria e a prática, mais especificamente entre as ciências básicas e a clínica, levando a uma formação fragmentada, em que os conhecimentos vêm despidos de seus processos e sentidos, não propiciando uma visão integral do indivíduo e de seu processo saúde-doença. Esse modelo de ensino das escolas médicas, com currículo flexneriano, vem sendo discutido em todo o mundo ${ }^{21,22}$. Tal fato, evidenciado nas falas a seguir, tem sido apontado como um importante desafio a ser enfrentado no ensino médico, com algumas iniciativas de mudanças nas estruturas curriculares, visto que se reflete em dicotomias, também, no que diz respeito aos conceitos de saúde e doença ${ }^{23}$.

[...] a gente tem muita dificuldade de visualizar o conhecimento que está sendo adquirido para o futuro.
A minha proposta é exatamente essa mudança [...] que a dicotomização deixe de existir, que deveras nos prejudica ao longo do curso; a gente inicia com a teoria desarticulada com a nossa prática, que serve pouco para nosso futuro e depois a gente se torna meros "tocadores" de serviços.

Para Freire ${ }^{24}$, a interação do estudante com a comunidade propicia a formação de um profissional que pretende trabalhar num horizonte dialógico e, por isso, mais eticamente envolvido com a sociedade. A ideia da articulação entre a universidade e o sistema de saúde na comunidade já é defendida por muitos ${ }^{25}$ (p. 27-31), conforme preconizam as DCNs, e parece ser uma realidade nas experiências exitosas no curso de Medicina da $\operatorname{UFRN}^{26}$ (p. 27-34).

Neste estudo, observamos que os estudantes, conforme suas falas, vivenciam o contato com a comunidade como uma oportunidade de compreender o paciente e entender sua doença dentro do contexto social:

Essa experiência na comunidade pra mim foi um ato de humanização que durante nosso curso a gente vê muito pouco.

Posso acrescentar que a experiência do estágio em Santa Cruz (interior do RN) contribuiu bastante para meu aprendizado fora da universidade e abriu caminhos para que eu pudesse agir como um verdadeiro profissional, mais humano, mais realista.

Na formação dos profissionais de saúde, é necessário, pois, propiciar oportunidades que favoreçam o contato dos estudantes com os problemas reais, de forma a dar sentido ao que se aprende/ensina. Para atingir esse objetivo, algumas estratégias são enfatizadas como facilitadoras, tal como a multiplicidade de cenários para o processo de ensino-aprendizagem que possa promover a interdisciplinaridade e a aprendizagem interprofissional $^{27,28}$. Essa estratégia do contato do estudante com a comunidade, por meio da inserção das atividades de ensino nos cenários do SUS, tem encontrado resistência de parcela significativa dos professores, sobretudo nas escolas mais tradicionais, pelo próprio modelo de sua formação ${ }^{29}$ (p. 125).

Neste estudo, no entanto, conforme demonstram as falas a seguir, os estudantes expõem a importância do trabalho em equipe e o papel da integralidade do atendimento no contexto da humanização dentro da formação médica:

Eu observei isso em Santa Cruz (local onde se realiza o internato rural), não sei vocês, mas a gente tinha as equipes de atenção básica sem uma fragmentação tão importante, tão notória. 
OSUS é uma boa maneira de adotar essa nova tendência de aproximação, de integralidade, é um modelo que visa romper com a fragmentação da atenção à saúde, ele visa a um atendimento integral.

Outro aspecto percebido pelos estudantes no tocante às relações humanas na formação médica foi o contato com os professores. De suas falas emergiram duas subcategorias antagônicas em seu significado: professor modelo e relações assimétricas. Isto reflete a relação dialógica existente entre os papéis historicamente construídos para professor e estudante (o primeiro sendo referência para o segundo) e, por outro lado, processos decorrentes das diversas assimetrias (de poder e conhecimento) que permeiam o processo de ensino-aprendizagem. A figura do "professor modelo" se apresentou com veemência nas falas dos estudantes a seguir:

Eles, pra mim, são um exemplo de vivência e de sabedoria, pois pra mim não precisa expelir conhecimento pra mostrar que sabe, mas ser humano e humilde pra saber passar o conteúdo.

Eu acrescentaria que é, por exemplo, nesses professores, que procuram dar o melhor de si, que me espelho para poder seguir nessa profissão que a gente escolheu.

De modo contrário, as relações assimétricas estudante-professor também foram perceptíveis:

[...] o problema que eu acho é que eles esquecem e precisam saber que o resto do mundo também pensa.

Eu iria mais adiante, pra não dizer excesso de arrogância, muitos chegam a lembrar que eles são “Dr. Fulano de tal" e não têm tempo a perder com certas perguntas ou dúvidas sem sentido.

[...] (alguns) agem com um despotismo descabido, não aceitando nenhum comentário, mesmo porque, pra eles, nunca sabemos de nada e não somos capazes de pesquisar ou buscar informações sobre o assunto que eles tanto dizem saber.

Nessa relação estudante/professor, alguns autores sustentam que este último, além de atuar como um modelo para o estudante (processo de identificação) por intermédio de suas atitudes, gestos e comportamentos, deve ter em mente que tais processos se repetirão no relacionamento do futuro médico com seus pacientes. Essa relação deve ser tão valorizada quanto aquela que esse professor estabelece com seus pacientes ${ }^{30,31}$.

Isso denota que, para exercer seu papel de facilitador da aprendizagem, o professor precisa assumir uma postura acolhe- dora, que considere os conhecimentos prévios dos estudantes e suas demandas particulares. Assim, o estudante deve assumir o papel de agente de aprendizagem, e o professor, de orientador e facilitador. Na perspectiva da formação integral do estudante, para o trabalho em saúde, o professor necessita desenvolver habilidades pedagógicas voltadas à incorporação de metodologias de ensino-aprendizagem que favoreçam a troca, a construção do conhecimento e o protagonismo dos estudantes na apropriação de saberes científicos, éticos e políticos ${ }^{32}$ (p. 95).

Em função disso, os fóruns de educação médica têm debatido temas como a construção ativa e permanente do conhecimento pelo estudante, a interdisciplinaridade, a humanização da assistência à saúde e a necessidade de um ambiente acolhedor para os estudantes nas escolas de Medicina, para auxiliar os jovens a superar suas ansiedades e refletir sobre suas práticas. Quando há carência de professores, que, além de tecnicamente competentes, tenham atitudes que sirvam de modelo para a prática profissional, o enfrentamento ocorrerá a partir dos mecanismos de defesa do ego, sendo a negação, a intelectualização e a dissociação os mais acionados, levando o jovem estudante a se alienar do humano e a se isolar do paciente ${ }^{11,33}$.

\section{CONSIDERAÇÕES FINAIS}

Considerando o processo de mudança curricular que vem sendo implantado no curso de Medicina da UFRN, percebe-se, com este estudo, a importância da implementação efetiva de um eixo humanístico na estrutura curricular que leve em conta a abordagem dos aspectos apontados.

Promover saúde e humanizar a sua atenção são trabalhos processuais, de longo prazo, dinâmicos e intimamente relacionados ao contexto em que se desenvolvem, e cujo diagnóstico é importante para propor ações adequadas. No contexto da educação médica, visualizar o eixo humanístico significa romper com estruturas fragmentadas dos cursos, como disciplinas isoladas e não integradas, com a tendência à especialização precoce do estudante, com a inserção tardia deste na prática, com a utilização de metodologias de ensino baseadas somente na transmissão de conteúdos e com a dissociação entre a formação e as necessidades sociais.

O curso de Medicina da UFRN define como seu egresso um profissional com formação geral, humanista, crítica e reflexiva, apto a atuar na sociedade em que está inserido como promotor da saúde integral do ser humano. Entretanto, a despeito do avanço do projeto pedagógico, ainda se evidencia um descompasso entre os preceitos estabelecidos e a implementação efetiva do processo, fato que motivou a realização desta pesquisa. 
Dessa forma, entendemos que, para que o estudante possa desenvolver uma atitude que assista o paciente de forma integral, contemplando seus aspectos psicológicos, sociais e ambientais, é necessário que vivencie práticas humanizadas desde o início de sua formação.

\section{REFERÊNCIAS}

1 Nogueira-Martins LA, Bodega NJ. Saúde mental dos profissionais da Saúde. Rev Bras Med Trab. 2003;1:56-68.

2. Bastos LAM, Proença MA. A prática anatômica e a formação médica. Rev Panam Salud Publica. 2000;7(6):395-402.

3. Travesso-Yepez M, Morais NA. Reivindicando a subjetividade dos usuários da Rede Básica de Saúde: para uma humanização do atendimento. Cad Saúde Pública. 2004;20(1):80-88.

4. Almeida HO, Alves NM, Costa MP, Trindade EMV, Muza GM. Desenvolvendo competências em Comunicação: uma experiência com a Medicina Narrativa. Rev Bras Educ Med. 2005;29(3):208-216.

5. Minayo MCS. O desafio do conhecimento: pesquisa qualitativa em saúde. 4ª ed. São Paulo: Hucitec; 2004.

6. Fontanella BJ, Ricas J, Turato ER. Amostragem por saturação em pesquisas qualitativas em saúde: contribuições teóricas. Cad Saúde Pública. 2008;24:17-27.

7. Nuto SAS, Nations MK, Costa ICC. Aspectos culturais na compreensão da periodontite crônica: um estudo qualitativo. Cad Saúde Pública. 2007;23(3):681-90.

8. Bardin L. Análise de conteúdo. Lisboa: Edições 70; 1977.

9. Bauer MW, Aarts B. A construção do corpus: um princípio para a coleta de dados qualitativos. In: Bauer MW, Gaskell G, (eds.). Pesquisa qualitativa com texto: imagem e som: um manual prático. Petrópolis: Vozes; 2002. p.39-63.

10. Ramos-Cerqueira ATA, Lima MCP. A formação da identidade do médico: implicações para o ensino de graduação em medicina. Interface Comum Saúde Educ. 2002;6(11):107-16.

11. Ronzani TM, Ribeiro MS. Identidade e formação profissional dos médicos. Rev Bras Educ Med. 2003;27(3):229-36.

12. Pitkälä KH, Mäntyranta T. Feelings related to first patient experiences in medical school: a qualitative study on students' personal portfolios. Patient Educ Couns. 2004;54(2):171-77.

13. Pitkälä KH, Mäntyranta T. Professional socialization revised: medical students' own conceptions related to adoption of the future physician's role-a qualitative study. Med Teach. 2003;25(2):155-60.
14. Balint M. O médico, seu paciente e a doença. Rio de Janeiro: Atheneu; 1975.

15. Goldberg JL. Humanism or professionalism? The White Coat Ceremony and medical education. Acad Med. 2008;83(8):715-22.

16. Turini B, Martins Neto D, Tavares MS, Nunes SOB, Silva VLM, Thomson Z. Comunicação no ensino médico: estruturação, experiência e desafios em novos currículos médicos. Rev Bras Educ Med. 2008;32(2):264-70.

17. Silva JFRS. A formação do médico. In: De Marco MA (org.). A face humana da medicina: do modelo biomédico ao modelo biopsicossocial. São Paulo: Casa do Psicólogo; 2003.

18. Ribeiro MM, Krupat E, Amaral CF. Brazilian medical students' attitudes towards patient-centered care. Med Teach. 2007;3:1-5.

19. Bardes CL, Hayes JG. "Are the teachers teaching? Measuring the educational activities of Clinical Faculty". Acad Med. 1995;70(2):111-14.

20. Candau VMF. A Didática em questão. Petrópolis: Vozes 1996.

21. Boudreau JD, Cassell EJ, Fuks A. A healing curriculum. Med Educ. 2007;41(12):1193-201.

22. Spencer AL, Brosenitsch T, Levine AS, Kanter SL. Back to the basic sciences: an innovative approach to teaching senior medical students how best to integrate basic science and clinical medicine. Acad Med. 2008;83(7):662-9.

23. Christianson CE, Mcbride RB, Vari RC, Olson L, Wilson HD. From traditional to patient-centered learning: curriculum change as an intervention for changing institutional culture and promoting professionalism in undergraduate medical education. Acad Med. 2007;82(11):1079-88.

24. Freire P. Pedagogia da autonomia: saberes necessários à prática educativa. $3^{\underline{a}}$ ed. São Paulo: Paz e Terra; 2004.

25. Blank D. A propósito de cenários e atores: de que peça estamos falando? Uma luz diferente sobre o cenário da prática dos médicos em formação. Rev Bras Educ Med. 2006;30(1):27-31.

26. Silva TDNC, Nunes RAS, Martins Jr ANN, Tertulino FF, Silva CAN, Maranhão TMO. Atuação dos estudantes de medicina da Universidade Federal do Rio Grande do Norte na rede básica de saúde - Relato de experiência. Revista Eletrônica Pesquisa Médica. 2007;1(4):27-34.

27. Costa AM. Integralidade na atenção e no cuidado à saúde. Saúde soc 2004; 13: 5-15.

28. Batista SHS. A interdisciplinaridade no ensino médico. Rev Bras Educ Med. 2006;30(1):39-46. 
29. Ciuffo RS, Ribeiro VMB. Sistema Único de Saúde e a formação dos médicos: um diálogo possível? Interface Comun Saúde Educ. 2008 12:125-40.

30. Millan LR, De Marco OL, Rossi E, Millan MPB, Arruda PCV. Alguns aspectos psicológicos ligados à formação médica. In: O universo psicológico do futuro médico: vocação, vicissitudes e perspectivas. São Paulo: Casa do Psicólogo; 1999.

31. Tavares FM. As contribuições da Medicina Psicossomática à formação médica. Rev Bras Educ Med. 2005;29(1):64-9.

32. Santeiro TV, Santeiro FRM, Andrade IR. Professor facilitador e inibidor da criatividade segundo universitários. Psicol Estud. 2004;9:95-102.

33. Navarro EC. Formando médicos da pessoa - o resgate das relações médico-paciente e professor-aluno. Rev Bras Educ Med. 1997;21(2-3):22-8.

\section{CONTRIBUIÇÃO DOS AUTORES}

Os autores Antônia Núbia de Oliveira Alves, Simone da Nóbrega Tomaz Moreira, George Dantas de Azevedo, Vera Maria da Rocha e Maria José Pereira Vilar participaram da concepção do desenho deste estudo, da análise e interpretação dos dados, redação e revisão final.

\section{CONFLITO DE INTERESSES}

Declarou não haver.

\section{ENDEREÇO PARA CORRESPONDÊNCIA}

Universidade Federal do Rio Grande do Norte Departamento de Ciências Sociais.

Av. Cel. Gustavo Cordeiro de Farias

Petrópolis - Natal

CEP. 59010-180 RN

Cx Postal 244 